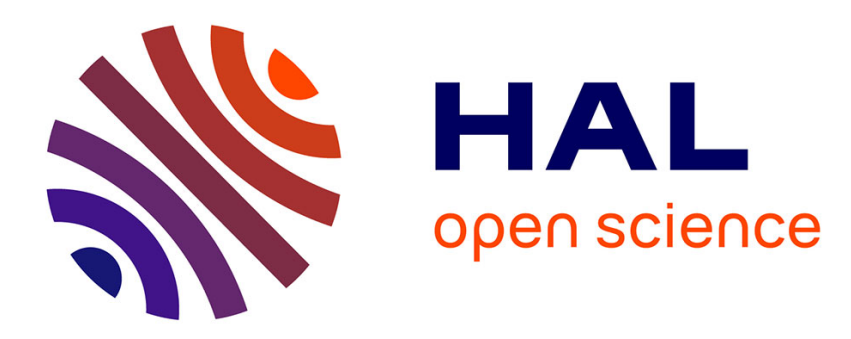

\title{
Theoretical aspects of oxidation of composite materials
}

Ge Wang

\section{To cite this version:}

Ge Wang. Theoretical aspects of oxidation of composite materials. Journal de Physique IV Proceedings, 1993, 03 (C9), pp.C9-873-C9-880. 10.1051/jp4:1993990 . jpa-00252432

\section{HAL Id: jpa-00252432 https://hal.science/jpa-00252432}

Submitted on 1 Jan 1993

HAL is a multi-disciplinary open access archive for the deposit and dissemination of scientific research documents, whether they are published or not. The documents may come from teaching and research institutions in France or abroad, or from public or private research centers.
L'archive ouverte pluridisciplinaire HAL, est destinée au dépôt et à la diffusion de documents scientifiques de niveau recherche, publiés ou non, émanant des établissements d'enseignement et de recherche français ou étrangers, des laboratoires publics ou privés. 


\title{
Theoretical aspects of oxidation of composite materials
}

\author{
Ge Wang
}

Department of Materials Science and Engineering, The Ohio State University, Columbus, $\mathrm{OH}$ 43210, U.S.A.

\begin{abstract}
Relationships between the high-temperature oxidation behavior and the composite architecture (shape, size, volume fraction, and orientation of the reinforcement phase) are proposed.
\end{abstract}

\section{Introduction.}

Composite materials represent a new generation of high-temperature structural materials. The importance of composite materials is reflected in the significant amount of research effort that has been expended in recent years to characterize their mechanical properties. Interestingly, however, research directly aimed at the high-temperature environmental durability of composite materials has been scarce. For example, El Dahshan et al. [1] oxidized Ni-20Cr containing W fibers, Park and Simkovich [2] oxidized $\mathrm{Fe}-\mathrm{Cr}$ alloys containing $\mathrm{Si}_{3} \mathrm{~N}_{4}$ particles, Wagner and Simkovich [3] oxidized $\mathrm{Co}-\mathrm{Gr}$ alloys containing $\mathrm{Si}_{3} \mathrm{~N}_{4}$ particles, Lin et al. [4] oxidized $\mathrm{Al}_{2} \mathrm{O}_{3}$-SiC whisker composites, Korinko et al. [5] oxidized $\mathrm{NiAl} / \mathrm{TiB}_{2}$ composites, and Fish and Duquette [6] oxidized a TiAl/ $\mathrm{Al}_{2} \mathrm{O}_{3}$ whisker composite. In addition to limited experimental studies, little theoretical work has been done to establish a proper foundation for understanding the high-temperature oxidation behavior of composite materials. Qualitative treatments of the oxidation behavior of multiphase materials have been given by Stringer $e t$ al. [7] and Bastow et al. [8]. Semi-quantitative treatments of the oxidation behavior of binary alloys have been presented by Wahl [9], and Wang et al. [10].

The purpose of this paper is to analyze both the possible stability diagrams and the oxidation kinetics involved in the high-temperature oxidation of a composite structure. In particular, the diffusional flux in the matrix phase to support the exclusive formation of a protective scale are related to the architecture of the composite (i.e. shape, size, volume fraction, and orientation of the reinforcements).

\section{Thermodynamics.}

The oxidation tendency of a material is greatly dependent on the thermodynamics of the reaction. In most cases, this reaction tendency can be presented graphically at a given temperature as a function of the material composition and oxygen activity. Such a thermodynamic representation is called a "stability diagram" in the oxidation community, and has been widely used in analyzing the oxidation behavior of various monolithic materials, especially binary alloys, and more recently for intermetallic compounds [11]. 
The construction of a stability diagram for a composite material, offers two major challenges. First, a composite material is generally a multicomponent system, so that a twodimensional graphic representation can hardly describe the entire system. Second, a composite material is a multiphase system, which includes not only a matrix phase and a reinforcement phase but in some cases also one or more interfacial intermediate phase(s) between the matrix and the reinforcement phase. Furthermore, the entire composite system may not be at thermodynamic equilibrium, so that some serious interfacial reactions between the matrix and the reinforcement phase may occur in addition to surface oxidation at the service temperatures. In the following analysis, the composite material is simplified to a model system which can be more readily analyzed based on our understanding on alloy oxidation.

Let us consider a simple two-phase system containing a matrix phase $\mathrm{M}$ and a reinforcement phase $\mathrm{R}$ with no stable intermediate phase between them. The matrix phase contains primarily component $A$ with a very limited solubility for component $B$; likewise, the reinforcement phase contains primarily component $B$ with a very limited solubility for component $A$. Assume that the component $\mathrm{B}$ forms a more stable oxide $\mathrm{BO}$ than oxide $\mathrm{AO}$ (the oxide stoichiometries are conveniently assumed to be $\mathrm{AO}$ and $\mathrm{BO}$ ). There are two possible kinds of stability diagrams for such a simple composite. In the stability diagram shown in figure 1, oxides $\mathrm{AO}$ and $\mathrm{BO}$ form a continuous solid solution. In the stability diagram shown in figure 2, a very limited solubility for the other component is permitted for each oxide. Again, no stable intermediate oxide compound forms.
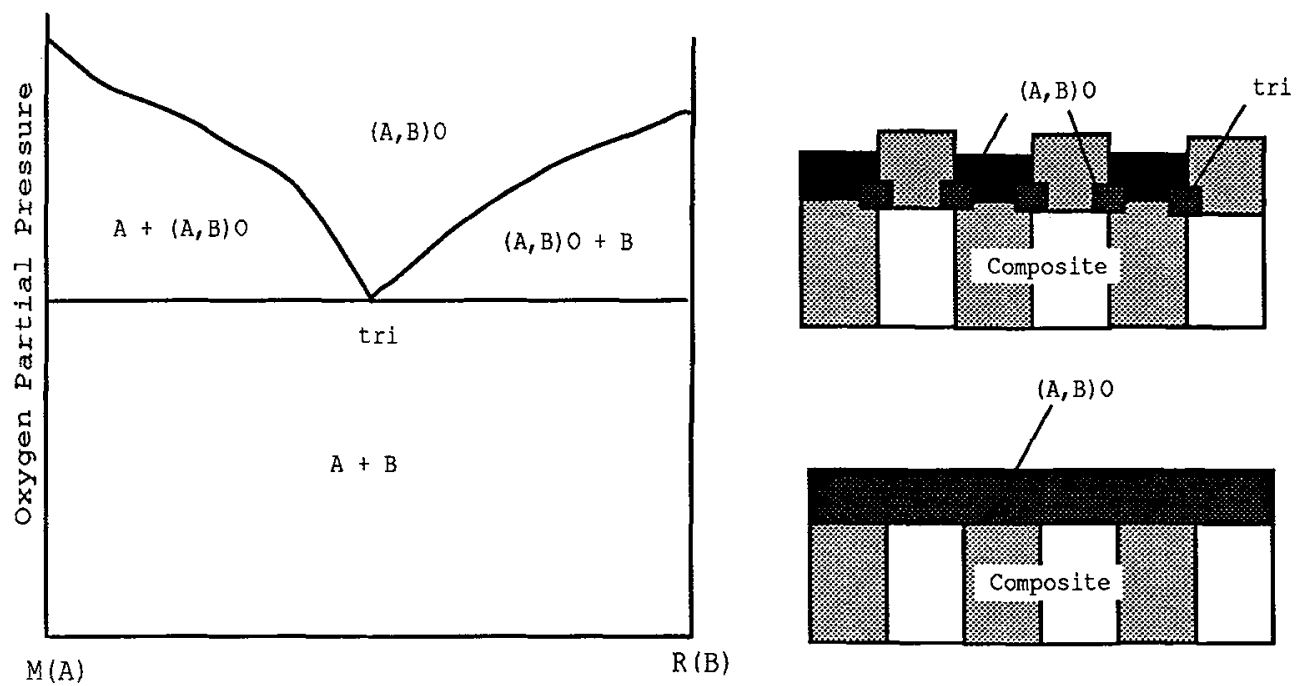

(a)

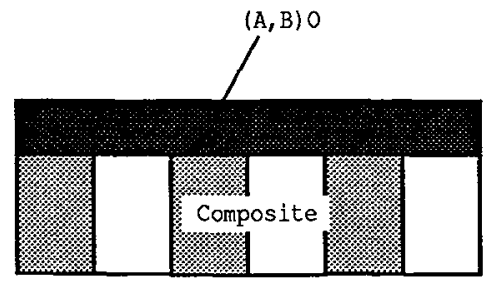

(b)

Fig. 1. - Stability diagram of a composite system forming a solid solution oxide, and possible oxide scale morphologies, where $M$ is the A-rich matrix phase and $R$ is the B-rich reinforcement phase: a) morphology developed at an early stage; b) morphology developed at a later stage.

In figure 1, oxides $\mathrm{AO}$ and $\mathrm{BO}$ form initially on the matrix and the reinforcement phases, respectively, but at the triple point (tri, see Fig. la), AO and BO react to form the solid solution $(A, B) O$. This solid solution keeps growing and eventually covers the entire surface of the composite (see Fig. 1b) as indicated by the stability diagram. If one of the oxides (either 

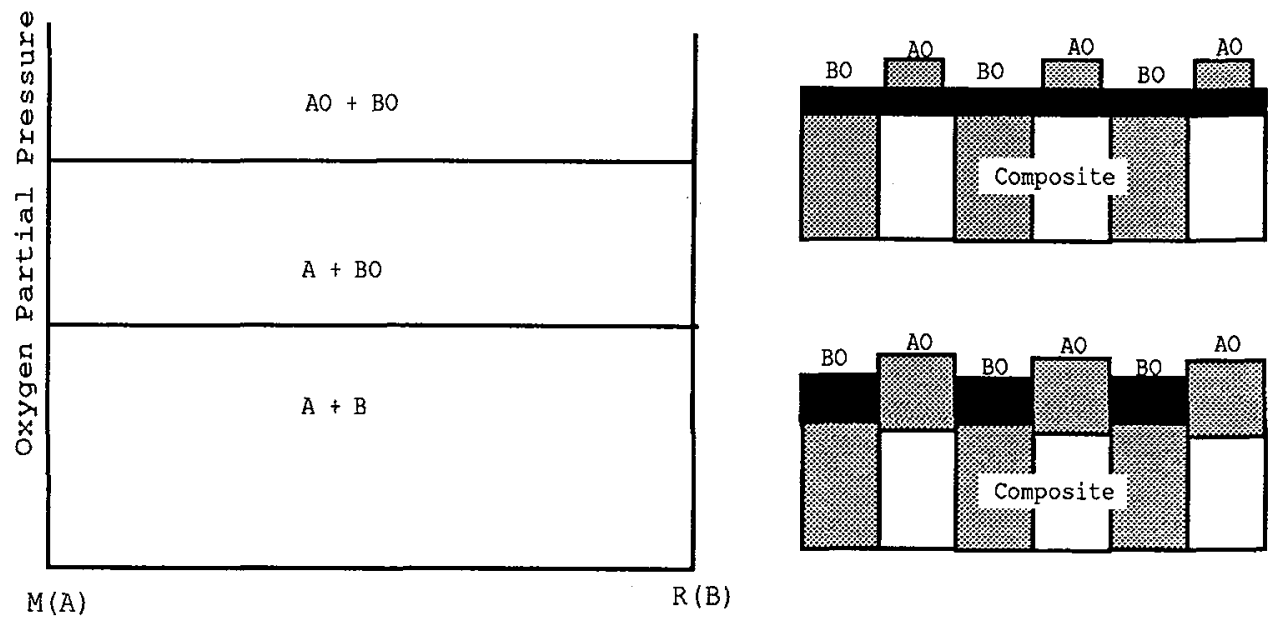

Fig. 2. - Stability diagram of a composite system forming two nearly-insoluble oxides, and possible oxide scale morphologies: a) protective oxide forms to slow down further oxidation; b) two phases oxidize independently.

$\mathrm{AO}$ or $\mathrm{BO}$ ) has poor oxidation resistance, it is unlikely that the solid solution oxide will be protective, since the defect structure from the less-resistant oxide will be inherited by the solid solution.

In figure 2, the most stable oxide $\mathrm{BO}$ forms initially on both the matrix phase and the reinforcement phase. Stringer et al. [7] have pointed out that the same oxide should form on both phases of a two-phase alloy, since at equilibrium the two alloy phases should have identical chemical activities for each component. If $\mathrm{BO}$ is highly oxidation-resistant, $\mathrm{AO}$ will either not form or stop growing.

Otherwise, A may readily diffuse through the non-protective BO to form an AO layer on top of the BO (see Fig. 2a), as often observed in alloy oxidation. However, in some other situation, an independent oxidation for each phase may be observed, i.e. AO forms primarily on phase $\mathrm{M}$ (A-rich) and BO forms primarily on phase $\mathrm{R}$ (B-rich) as shown in figure $2 \mathrm{~b}$. Whether a protective $\mathrm{BO}$ forms on both phases or $\mathrm{AO}$ and $\mathrm{BO}$ form on each phase independently is largely a consequence of kinetic factors, which will be discussed in the following sections.

\section{Kinetics.}

The oxidation of a single phase alloy may lead to either a mixed oxide scale on the surface or the exclusive formation of the most stable oxide of the alloy constituents, which in most cases is a slow-growing protective oxide scale. Wagner [12] established a criterion for the exclusive formation of the protective scale on a binary single-phase alloy by balancing the supply of the more reactive constituent migrating from the bulk of the alloy to the alloy/scale interface and the consumption of this constituent at the alloy/scale interface to form its scale. The critical concentration of the alloy constituent necessary for the enhanced oxidation resistance in a single phase alloy is commonly known as the Wagner's criterion for the exclusive formation of a protective scale.

When a composite material is exposed to an oxidizing environment, each phase in the 
composite will oxidize at different scaling kinetics, but Wagner's criterion may be applied to each phase separately. If Wagner's criterion for the exclusive formation of a particular oxide is satisfied for each of the phases, then a continuous layer of this oxide may form exclusively on the composite. Otherwise, if Wagner's criterion is satisfied for only one of the two phases, each phase may oxidize in a different manner, e.g., the reinforcement phase may oxidize slowly due to the formation of the protective oxide while a fast-growing oxide may form on the matrix phase, or vice-versa. However, there are some cases where Wagner's criterion is not satisfied for one of the two phases, yet a given protective scale forms on the entire material [13]. As discussed later, this can be attributed to the interaction between the diffusion fields from each phase, and there are three possible situations.

3.1 NO INTERACTION BETWEEN THE MATRIX PHASES AND THE REINFORCEMENT PHASE. - In this case, the diffusion fields of the two phases in the composite are not overlapping, so that the two phases oxidize independently. Additive oxidation kinetics can be applied to this situation, which introduces another "law of mixtures" for composite materials. If both oxides obey the parabolic-growth laws, the global kinetics will also be parabolic, and the following relation exists between the parabolic constants:

$$
\sqrt{k_{\text {total }}}=\phi_{\mathrm{M}} \sqrt{k_{\mathrm{M}}}+\phi_{\mathrm{R}} \sqrt{k_{\mathrm{R}}}
$$

where the $k_{\text {total }}, k_{\mathrm{M}}$, and $k_{\mathrm{R}}$ are the parabolic rate constants for scale growth on the composite, the matrix phase, and the reinforcement phase, respectively; $\phi_{\mathrm{M}}$ and $\phi_{\mathrm{R}}$ are the volume fractions of each phase. Knowing that $\phi_{\mathrm{M}}+\phi_{\mathrm{R}}=1$, and substituting this into equation (1), the overall parabolic rate constant for the composite material can be restated as:

$$
\frac{k_{\text {total }}}{k_{\mathrm{M}}}=\left(\sqrt{\frac{k_{\mathrm{R}}}{k_{\mathrm{M}}}}-1\right)^{2} \phi_{\mathrm{R}}^{2}+2\left(\sqrt{\frac{k_{\mathrm{R}}}{k_{\mathrm{M}}}}-1\right) \phi_{\mathrm{R}}+1
$$

This relation can be regarded as the "law of mixtures" for the oxidation of composite materials when there is no interaction between the two phases; this relation is shown in figure 3. Logarithmic values of the $k_{\text {total }}$-to- $k_{\mathrm{M}}$ ratio are presented in this figure for a clear illustration. As indicated in figure 3 , a higher $k_{\mathrm{R}}$-to- $k_{\mathrm{M}}$ ratio gives rise a higher global rate constant with increasing the volume fraction of the reinforcement phase, whereas a lower $k_{\mathrm{R}}$-to- $k_{\mathrm{M}}$ ratio offers a reduced total oxidation rate constant with increasing the volume fraction of $R$. The apparent activation energy of the overall rate constant is also a combination of the activation energies for each phase.

$$
Q_{\text {total }}=\phi_{\mathrm{M}} \sqrt{\frac{k_{\mathrm{M}}}{k_{\text {total }}}} Q_{\mathrm{M}}+\phi_{\mathrm{R}} \sqrt{\frac{k_{\mathrm{M}}}{k_{\text {total }}}} Q_{\mathrm{R}}
$$

where $Q$ 's are the activation energies. It can be noted that this "law of mixtures" for activation energies is slightly different from the one proposed for a multilayered-oxide scale by Gleeson et al. [14].

3.2 STRONG INTERACTION BETWEEN THE MATRIX PHASE AND THE REINFORCEMENT PHASE. In this case, the diffusion fields from the two phases overlap considerably. A denuded zone can be found near the surface, where the reinforcement phase quickly dissolves into the 


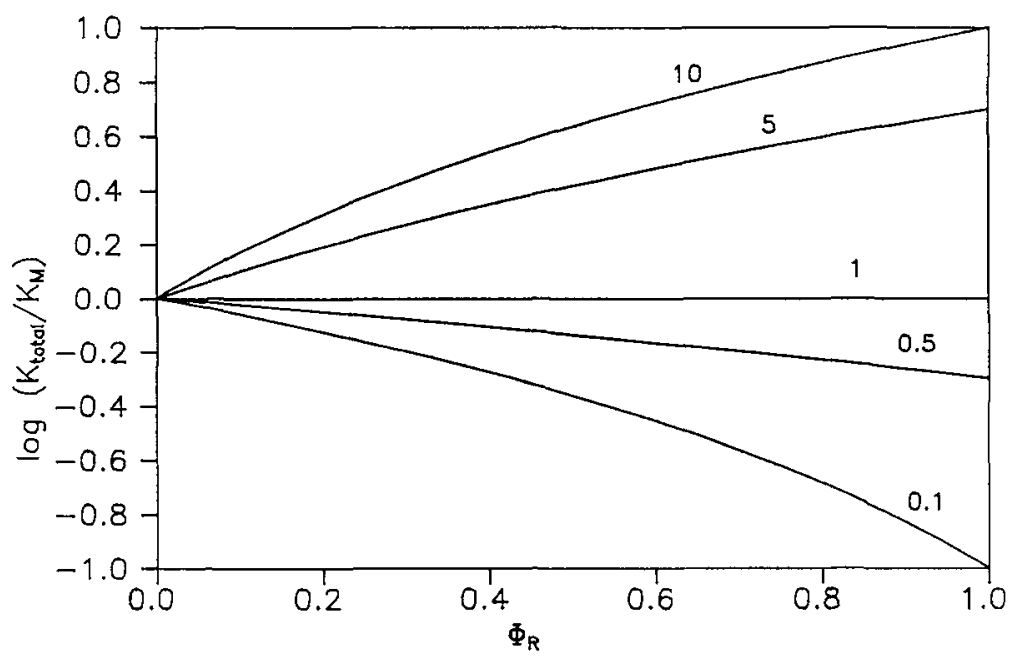

Fig. 3. - Additive oxidation kinetics, where $k_{\text {total }}$ is the parabolic rate constant for overall composite, $k_{\mathrm{M}}$ for matrix phase, and $k_{\mathrm{R}}$ for reinforcement. $\phi_{\mathrm{R}}$ is the volume fraction of the reinforcement. The values in the figure indicate the $k_{\mathrm{R}}-$ to $_{\mathrm{M}}$ ratios in the composite.

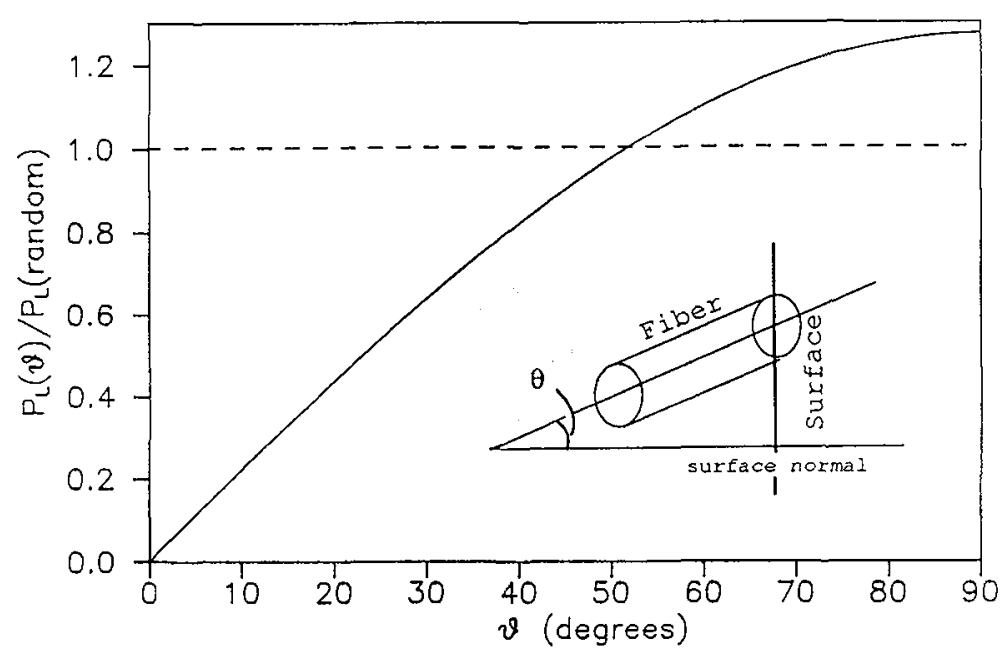

Fig. 4. $-P_{\mathbf{L}}(\theta)$ as a function of the orientation between the fiber and the surface. The angle $\theta$ is defined between the fiber orientation and the surface normal. $P_{\mathrm{L}}$ (random) is the $P_{\mathrm{L}}$ for random fiber orientation.

matrix phase to support a selective removal of one of the components at the oxidizing surface. Wahl [9] developed an anlaysis for a two-phase structure where a near-surface denuded zone develops by a quick dissolution of the second phase; this analysis can be readily applied to a composite structure where the rapid dissolution of the reinforcement phase occurs beneath the surface. By Wahl's criterion, the exclusive formation of the most stable and slow-growing 
oxide scale BO can be achieved, only if the following condition is met:

$$
\sqrt{N_{\mathrm{B}}^{0} N_{\mathrm{B}}^{\text {tot }}}>\frac{V}{V(\mathbf{B O})} \sqrt{\frac{\pi k_{\mathrm{p}}}{2 D}}=N_{\mathrm{B}}^{\mathrm{W}}
$$

where $N_{\mathrm{B}}^{0}$ and $N_{\mathrm{B}}^{\text {tot }}$ are the mole fractions of component B in the matrix phase and in the overall composite, respectively, $V$ and $V(\mathrm{BO})$ are the molar volumes of the composite material and of the oxide $\mathrm{BO}$, respectively, $k_{\mathrm{p}}$ is the parabolic rate constant for the growth of oxide $\mathrm{BO}, D$ is the interdiffusion coefficient for the matrix phase, and $N_{\mathrm{B}}^{\mathrm{W}}$ is the Wagner's critical concentration for the exclusive formation of oxide $\mathrm{BO}$ on the matrix phase. Wahl treated this two-phase system by a steady-state diffusion model with no consideration given for the architecture of the microstructure, i.e. the shape, size, and orientation of the second phase.

\subsection{LESS STRONG INTERACTION BETWEEN THE MATRIX PHASE AND THE REINFORCEMENT PHASE.}

- In most situations, a total dissolution of the reinforcement phase near the surface does not necessarily occur; however, the exclusive formation of the slow-growing oxide $\mathrm{BO}$ is still possible. A non-steady state diffusion analysis for a two-phase structure has been provided by Wang et al. [10]. In their analysis, an average diffusion flux from the two-phase structure to the surface was evaluated by considering the unidirectional diffusion in multiple diffusion columns, and the length of each column was related to the microstructure of the two-phase structure. Their analysis was able to relate the oxidation behavior of the two phase structure to the architecture of its second phase. The criterion for the exclusive formation of the protective oxide $\mathrm{BO}$ scale was found to be:

$$
P_{\mathrm{L}} \sqrt{D t}>\Phi\left(\frac{N_{\mathrm{B}}^{0}}{N_{\mathrm{B}}^{\mathrm{W}}}\right)
$$

where $P_{\mathrm{L}}$ is a microstructural parameter defined in quantitative metallography, which is used here to describe the number of intercepts per unit length of the interphase boundary by a linear probe. Further $D$ is the interdiffusion coefficient of the matrix phase, $t$ is time, $N_{\mathrm{B}}^{0}$ is the solubility of B in the matrix phase, and again $N_{\mathrm{B}}^{\mathrm{W}}$ is Wagner's critical concentration for the matrix. The function $\Phi()$ is a monotonically-decreasing function given in reference (10). The $P_{\mathrm{L}}$ can further be related to the volume fraction $\left(\phi_{\mathrm{R}}\right)$, the size, and the geometries of the reinforcement phase. For example, for a spherical phase with a radius $r, P_{\mathrm{L}}=\frac{3 \phi_{\mathrm{R}}}{2 r}$; for a cubic phase with an edge length $a, P_{\mathrm{L}}=\frac{3 \phi_{\mathrm{R}}}{a}$; for a cylindrical phase with a radius $r$ and length $l, P_{\mathrm{L}}=\frac{l+r}{l r} \phi_{\mathrm{R}}$. As can be seen from these relationships, a preferred composite architecture for a good oxidation resistance requires a higher $P_{\mathrm{L}}$ as well as a higher $N_{\mathrm{B}}^{0}$, which in turn requires a greater volume fraction and smaller dimensions of the second phase.

Generally, a fine, dense, and homogeneously-distributed reinforcement phase which is rich in the component forming a stable, slow-growing oxide should perform better than some other reinforcement incorporated otherwise into the matrix.

The orientation of the reinforcement phase in a composite material represents another important aspect of its architecture. According to quantitative metallography, $P_{\mathrm{L}}=\frac{2}{\pi} L_{\mathrm{A}}$, where $L_{\mathrm{A}}$ is another parameter in metallography called line length per unit area. By utilizing this relationship, it can then be shown that for a composite containing continuous straight 
fibers with a $\theta$ angle between the fiber orientation and the surface normal (shown in Fig. 4), the $P_{\mathrm{L}}(\theta)$-to- $P_{\mathrm{L}}$ (random) ratio is

$$
\frac{P_{\mathrm{L}}(\theta)}{P_{\mathrm{L}}(\text { random })}=\frac{4}{\pi} \sin (\theta)
$$

where $P_{\mathrm{L}}(\theta)$ is measured along the given $\theta$ direction, and $P_{\mathrm{L}}$ (random) is for a randomlyoriented fiber architecture. As shown in figure 4, for a surface with a $\theta$ value greater than about $52^{\circ}$ (fiber is nearly parallel to the surface), the configuration offers an enhanced oxidation protection over the random configuration, whereas for a surface with the orientation less than about $52^{\circ}$ with respect to the fiber direction (fiber is nearly perpendicular to the surface), the configuration yields a worse oxidation protection than the random configuration. This effect was observed by Stott et al. [15] in the oxidation of a directionallysolidified two-phase eutectic structure.

\section{Concluding remarks.}

The oxidation behavior of composite materials involves both the thermodynamics and diffusion kinetics. For a system which forms a solid solution oxide, an enhanced oxidation resistance in the composite material is unlikely. However, real systems exhibit more often the formation of a mixed-oxide compound (e.g. spinel) than the formation of a continuous solid solution. For the exclusive formation of a slow-growing protective oxide scale on a composite, not only is a sufficient solute solubility in the matrix required, but also a sufficient amount of solute-rich second phase is needed. Certain second-phase geometries and distributions are more desirable than the others, and a fiber orientation perpendicular to the oxidizing surface is not preferred. The value of $P_{\mathbf{L}} \sqrt{D t}$ represents an important parameter in a multiphase structure, which in fact describes the ratio between the solute-diffusion length in the matrix $(\sqrt{D t})$ and the average interval between the matrix/reinforcement boundaries (a parameter proportional to $P_{\mathrm{L}}^{-1}$ ). For a system where the diffusion length is too small when compared to the average-interphase-boundary interval, the two phases oxidize independently, and an additive relationship can be applied to the overall kinetics. For a system with strong interaction between the matrix and the reinforcement (i.e. a significant diffusion length in the matrix), a dissolution approximation (Wahl's treatment) may be adequate. However, for some composites, where the solute diffusion length in the matrix is comparable to the dimensions of the average-interphase-boundary interval, the relation between the oxidation behavior and the architecture of the composite material is more complex.

\section{Acknowledgements.}

The author would like to thank R.A. Rapp for his comments and constant encouragement, and B. Gleeson for helpful discussion. 


\section{References}

[1] el Dahshan M.E., Whittle D.P., Stringer J., Oxid. Met. 9 (1975) 45.

[2] PARK S.W., Simkovich G., Alternate Alloying for Environmental Resistance, G.R. Smolik, Banerrji Eds. (Metallurgical Soc., Warrendale, 1987) p. 233.

[3] WAGNer G.P., Simkovich G., Oxid. Met. 27 (1987) 157.

[4] Lin F., Marieb T., Morrone A., Nutt S., High Temperature/High Performance Composites, F.D. Lemkey et al. (Materials Research Society, Pittsburgh, 1988) p. 323.

[5] Korinko P.S., Alman D.E., STOloff N.S., DuQueTte D.J., Oxidation of Powder Processed $\mathrm{NiAl}$ and $\mathrm{NiAl} / \mathrm{TiB}_{2}$ Composites, MRS 1992 Spring Meeting (San Fransisco, April, 1992).

[6] FISH J.S., DuQUeTTE D.J., Oxidation of $\mathrm{TiAl} \mathrm{Al}_{2} \mathrm{O}_{3}$ Composites, this proceedings.

[7] STRINGER J., CORKISH P.S., WhitTle D.P., Stress Effects and the Oxidation of Metals, J.V. Cathcart Ed. (AIME New York, 1975) p. 75.

[8] BASTOW B.D., WOOD G.C., WhiTTLE P.D., Oxid. Met. 16 (1981) 1.

[9] WAHL G., Thin Solid Films 107 (1983) 417.

[10] Wang G., GLEESON B., Douglass D.L., Oxid. Met. 35 (1991) 333.

[11] RaHMel A., SPENCER P.J., Oxid. Met. 35 (1991) 53.

[12] WAGNER C., J. Electrochem. Soc. 99 (1952) 369.

[13] El Dahshan M.E., WhitTle D.P., StRinger J., Cobalt 4 (1974) 86.

[14] GleEson B., Douglass D.L., GeSmundo F., Oxide Met. 33 (1990) 425.

[15] Stott F.H., Wood G.C., Fountain J.G., Oxid. Met. 14 (1980) 31. 